\title{
FEATURE Engaging a community of interest in water quality protection: Anglers monitoring wadeable streams
}

\section{Jack E. Williams, Shawn Rummel, Jake Lemon, Matt Barney, Kyle Smith, Kurt Fesenmyer, and} Jerry Schoen

C itizen-based stream monitoring programs have been conducted for decades by local citizens concerned about pollution of their local streams and rivers. In recent years, public participation has increased dramatically as state and federal agencies have developed protocols for citizen science monitoring of stream condition and water quality (Nerbonne and Vondracek 2003; Newman et al. 2012). Furthering the trend has been the dramatic increase in Internet access, web mapping capabilities that facilitate data storage and display, and technological improvements in monitoring equipment (Newman et al. 2012). These developments have broadened the scope of what is feasible to monitor, while bringing down the cost of many monitoring efforts.

Anglers have a long history of participation in citizen science initiatives aimed at monitoring streams and improving fisheries. In the United States, anglerbased interest in water quality dates from at least 1926 when the Izaak Walton League of America launched water quality monitoring efforts in the eastern United States, which would spin off local programs like Maryland's Save Our Streams (Firehock and West 1995). In Oregon, anglers have collected scale samples from steelhead (Oncorhynchus mykiss) as part of an age study (Clemens 2015) and teamed up with agencies and insect conservation societies to monitor stream temperature and water quality (Ferguson 2013). In California, flyfishers

Jack E. Williams is the senior scientist for Trout Unlimited (TU) in Medford, Oregon. Shawn Rummel is the field and research manager for TU in Lock Haven, Pennsylvania. Jake Lemon is the eastern shale gas monitoring coordinator for TU in Bellefonte, Pennsylvania. Matt Barney is the senior programmer for TU in Boise, Idaho. Kyle Smith is the membership engagement manager for TU in Eugene, Oregon. Kurt Fesenmyer is the senior geographic information system specialist for TU in Boise, Idaho. Jerry Schoen is the director of outreach and education at the Water Resources Research Center at the University of Massachusetts in Amherst, Massachusetts. have monitored coastal steelhead streams for temperature and water chemistry and have collected fin clips as part of a study to determine genetic introgression of hatchery rainbow trout (O. mykiss) with wild steelhead (Jacobson et al. 2014). All of these projects share the common goal of involving anglers in collecting scientific data about stream conditions and fish populations to improve water quality and assist governmental agencies with their management responsibilities.

Trout Unlimited (TU), a member-based conservation organization, recognized that angler members constitute a vast and largely untapped resource of volunteers that should be motivated to help monitor and protect streams supporting trout and salmon. Currently, there are approximately $150,000 \mathrm{TU}$ members divided into 400 local chapters and 38 state-level councils across the country that participate in local stream rehabilitation and environmental education projects. Some chapters also participate in stream and fish population monitoring although such participation is not quantified by $\mathrm{TU}$ at the national level.

In 2010, members of TU's Pennsylvania State Council began monitoring water quality in response to concerns about how increased well drilling, fracking, and new infrastructure associated with developing the Marcellus Shale energy resources of the region could impact brook trout fishing. With expansion of angler-based monitoring programs within the organization, TU identified new "angler science opportunities" as a focus in the 2015 national strategic plan (www.tu.org/anglerscience). National conservation organizations such as TU realize the potential to develop more effective advocacy efforts as members become better informed about resource conditions through citizen science projects while increasing the capacity to collect useful data to further conservation strategies.

Although awareness of water quality impacts crosses a broad spectrum of the public, anglers have a vested interest in the quality and quantity of fish habitat necessary to support their recreational pursuits. Coldwater-dependent trout and salmon are of particular interest to many anglers, yet are among the most threatened fishes. Of 28 native trout taxa in the United States, 3 are extinct, 6 are listed pursuant to the Endangered Species Act, and most of the remainder occupy $25 \%$ or less of their historical range (Trout Unlimited 2015). As a group, fishes of the family Salmonidae (trout, salmon, grayling, and whitefishes) are widely distributed but also among the most sensitive aquatic species to invasive species, habitat disturbances, and poor water quality (Behnke 2002). The declining status of native trout reflects the conditions of our nation's streams, which according to a recent report of the US Environmental Protection Agency (2016) include 46\% of our nation's streams and rivers classified in "poor" biological condition.

Until recently, most anglers participating in citizen science have done so through programs that measure water quality. As angler-based monitoring opportunities expand and diversify, it is important to examine varying programs for their effectiveness and to better understand how to meet the growing needs and expectations of the angling public for citizen science involvement. Despite the potential for expanded angler participation, there have been no studies aimed at understanding how to translate angler interest in stream conditions and fish populations into greater participation in citizen science efforts.

Further, we suggest that memberbased organizations like TU need to better understand the most effective roles of their national staff in facilitating increased participation and conservation effectiveness. In particular, TU and similar organizations need to understand how to best utilize staff capabilities to provide technical assistance, train volunteers, and track and report results in these emerging programs. We describe two diverse angler-based citizen science case studies and describe lessons learned to expand angler-based citizen science efforts 
within member-based organizations. One case study involves a more geographically focused water quality monitoring effort to track emerging threats to brook trout fisheries from development of the Marcellus Shale gas fields in the midAtlantic region. The other case is an effort to monitor stream temperature in trout and salmon habitats across the country in response to a range of near-term habitat disturbances and longer-term threats imposed by climate change. Both projects were volunteer-initiated programs that have acquired support and guidance over time from the national TU organization.

\section{ANGLERS MONITORING FOR SHALE GAS DEVELOPMENT IMPACTS}

Spurred by the rapid expansion of shale gas development in Pennsylvania, the Eastern Shale Gas Monitoring Program was established in 2010 by TU volunteers and the Pennsylvania Council of TU.Trout Unlimited staff, volunteers, the Alliance for Aquatic Resource Monitoring based at Dickinson College, and other advisors collaborated to establish the goals, objectives, and monitoring protocols for the project. The two major objectives of the project are to engage anglers to (1) identify and report pollution events resulting from shale gas development and (2) collect baseline water quality data in areas projected for future development. These goals are being met through the following tasks: conducting outreach to TU chapters and other outdoor groups, training volunteers in water quality monitoring protocols, providing the necessary equipment, providing technical support to volunteers collecting water quality data, and maintaining an online results database. Priority locations for monitoring have been developed in Pennsylvania, Virginia, and West Virginia utilizing TU's Conservation Success Index (Williams et al. 2007; Fesenmyer 2014)(figure 1).

During times of higher gas prices and increased well drilling, the program focused primarily on water quality sampling of streams. With reduced well fracking activity caused by lower gas prices, volunteer efforts have shifted to monitoring stream sedimentation caused by pipeline construction as energy devel-

\section{Figure 1}

Monitoring priority for Pennsylvania and West Virginia subwatersheds as determined by trout presence and gas development activity.

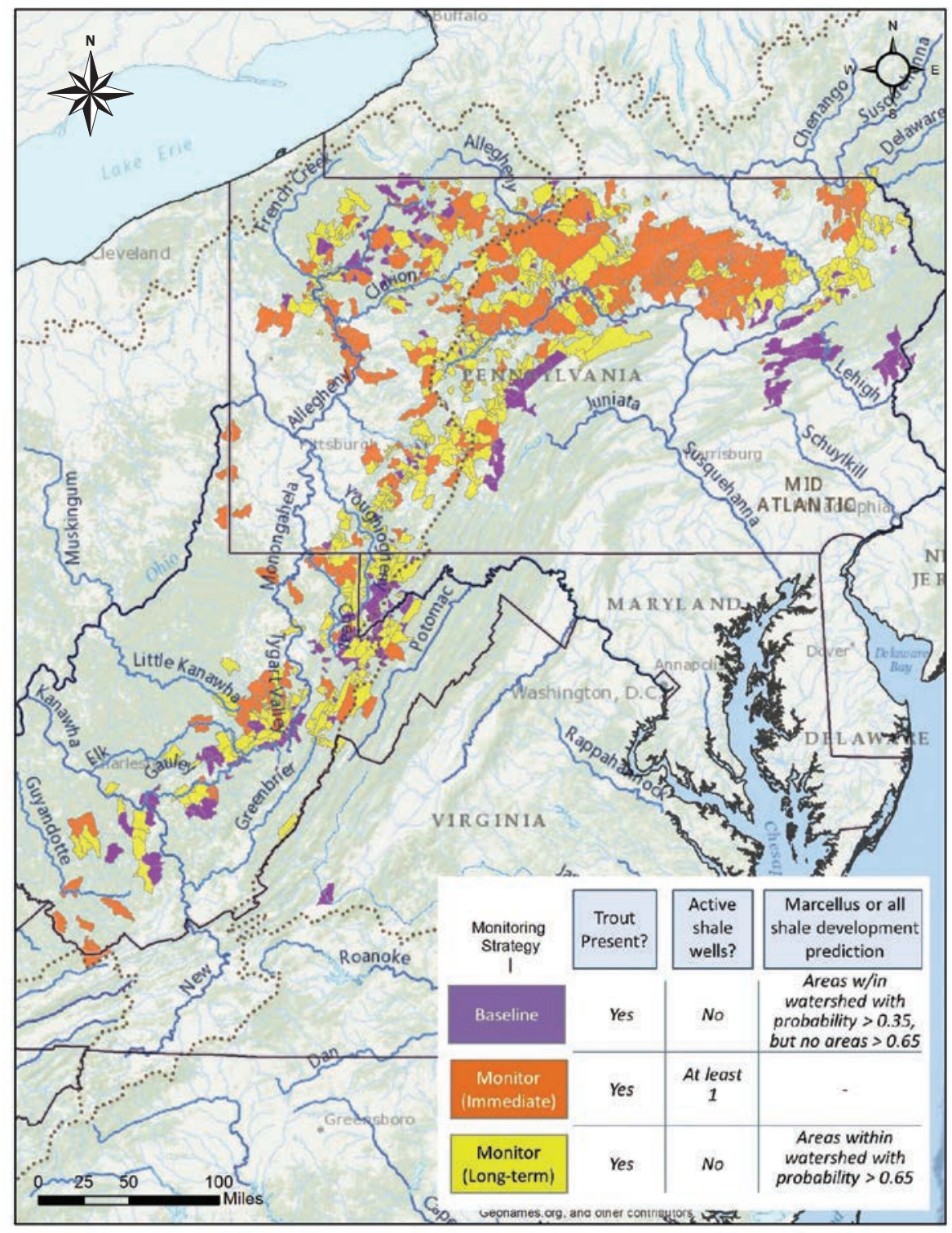

opment activity has shifted to moving supplies around rather than developing new wells (figure 2).

Staff from TU and partner organizations such as the West Virginia Rivers Coalition actively market the program through local media and social media outlets to attract volunteers. Currently, the program has 248 volunteers that conduct routine sampling at 424 sample sites throughout the three-state area. Volunteers are required to participate in a one-day field training course instructed by TU staff. The training course includes instruction on sample site selection, visual site assessment, calibration and use of monitoring equipment, and the water quality sample collection protocols (figure 3). During monitoring, volunteers complete measurements for water temperature, conductivity, total dissolved solids (TDS), flow, $\mathrm{pH}$, and turbidity and collect samples for laboratory analysis. Volunteer-collected data are entered into TU's online database and verified by TU staff. In addition, quality assurance/quality control samples are routinely collected, analyzed by one of TU's partner laboratories, and compared to the field measurements made by volunteers. 


\section{Figure 2}

Construction of a natural gas gathering line in West Virginia. During construction, volunteers focus on increased sedimentation from steep hillslopes and stream crossings. Photo by Dominion Pipeline Monitoring Coalition.

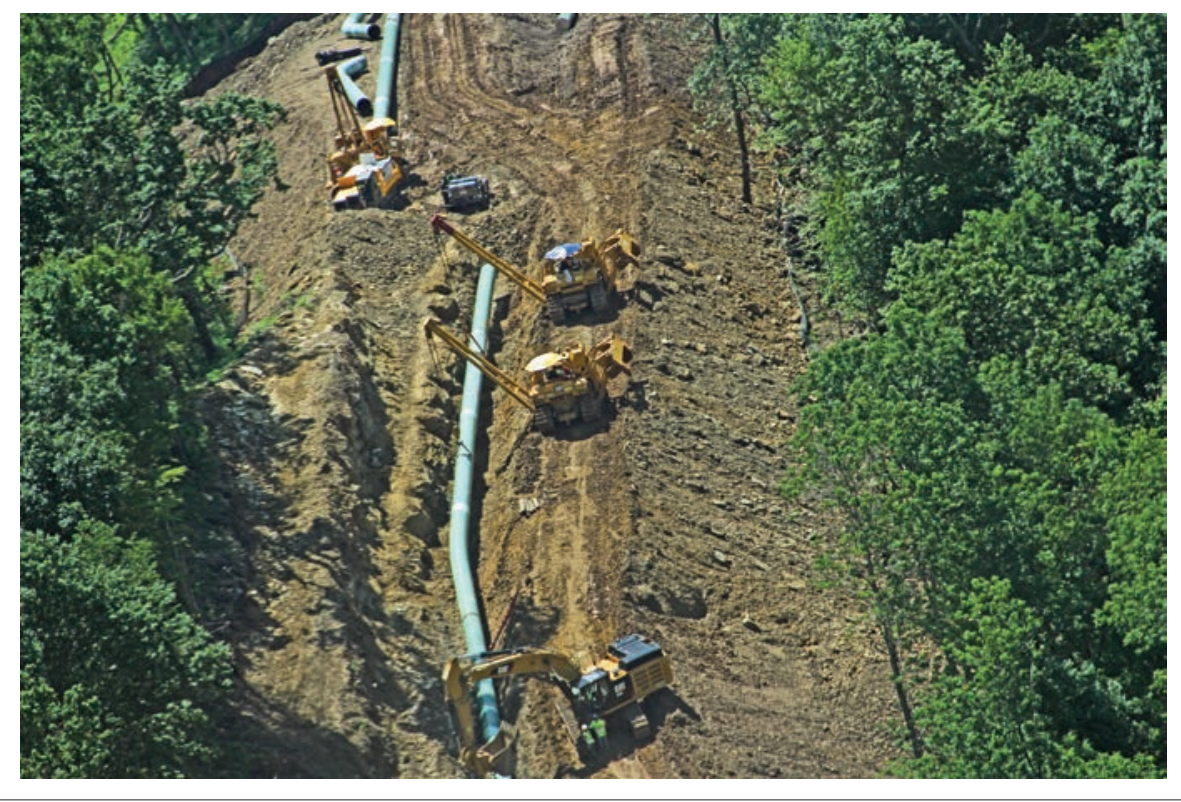

\section{Figure 3}

Refresher briefing as volunteers get ready for the Monongahela Watershed Snapshot Day event. Photo by Kathleen Tyner, West Virginia Rivers Coalition.

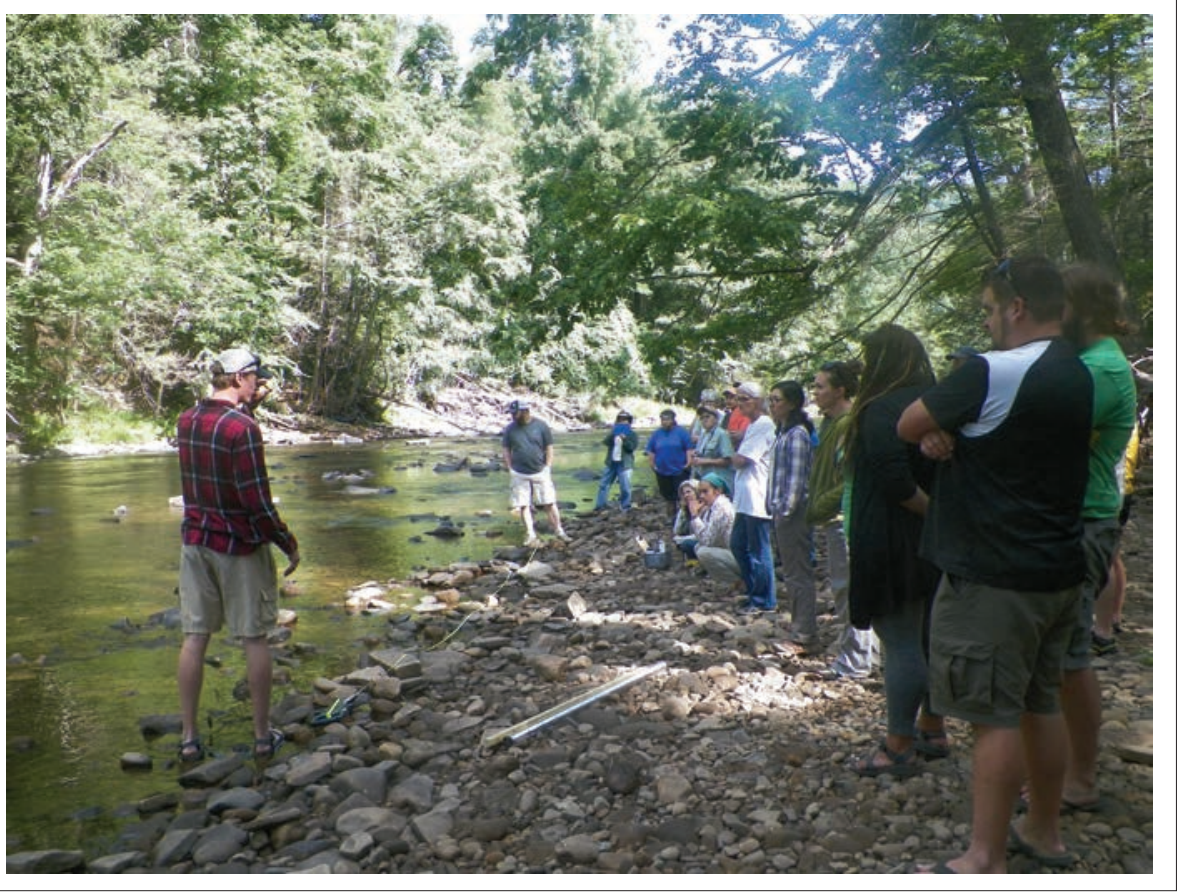

\section{SHALE GAS MONITORING OUTCOMES}

Data are utilized by state agencies to help monitor for pollution impacts associated with energy development. The primary benefit has been the early identification of pollution incidents and their mitigation. Water quality data also are currently being utilized by researchers at Pennsylvania State University to examine linkages between surface and groundwater contamination by analyzing samples for methane, and the data have been requested by researchers at the Massachusetts Institute of Technology for a study of soil and groundwater geochemistry.

Staff communicates the results of the program with volunteers through regular email updates and bimonthly conference calls to provide additional training and address any issues that may have arisen. Volunteer data are also made available to state agencies and academic institutions through the online database or staff.

The program has increased monitoring capabilities for state agencies while providing opportunities for individual participants to study their local streams. Participants receive valuable training and support to effectively monitor and protect their local waterways while developing relationships with people sharing an interest in coldwater conservation. The program has expanded TU's capacity to collect water quality data to protect coldwater streams and also created betterinformed local advocates for conservation.

Most monitoring is directed at conservation of trout streams in the region. The Eastern Shale Gas Monitoring Program has expanded the often limited capacity of state agencies to effectively monitor surface waters for potential impacts from shale gas development. TU staff has worked directly with state agencies to advocate for the utilization of volunteercollected data in management decisions and the early detection and response to pollution events. For example, data have been provided to the West Virginia Department of Environmental Protection for use in prioritizing agency monitoring and reporting under sections 303(d) and 305(b) of the Clean Water Act.

\section{ANGLERS MONITORING STREAM TEMPERATURES}

Trout and salmon need cold water. Monitoring stream temperatures is a relatively inexpensive and easy way for anglers to establish baseline temperatures, track long-term trends, assess the effectiveness of riparian restoration projects, and ensure that conditions comply with state and federal regulations. National TU staff provides guidance by performing analyses that target monitoring in 
areas where fish are likely to experience stress due to warming temperatures. In addition, these analyses ensure that local monitoring efforts fit into a larger context, contributing to regional or national stream temperature monitoring networks, such as US Forest Service's NorWeST project (http://www.fs.fed.us/rm/boise/ AWAE/projects/NorWeST.html).

Trout Unlimited staff develop training materials, equipment kits, and online resources, and they encourage participation in the program through presentations at local, regional, and national TU meetings. While many temperature monitoring protocols and instruments exist, TU's program promotes data loggers, which once installed, record stream temperatures hourly for up to five years. For consistency and quality assurance, TU has selected one data logger (the Onset Tidbit, Onset Computer Corporation, Bourne, Massachusetts) and one installation technique, and has developed a guidebook (http://www.tu.org/sites/default/files/ water-temperature-monitoring-v3-final. pdf) to facilitate self-instruction by angler scientists. For coordination across the large geography of trout distribution in the United States, staff has produced maps of priority locations for monitoring stream temperatures on the thermal margins of native trout distribution (figure 4), but also encourages consultation with local agencies and university scientists to assist volunteers in customizing monitoring protocols to their local situations. National staff provides necessary software, hardware, manuals, and maps in stream temperature kits for distribution to chapters (figure 5).

\section{STREAM TEMPERATURE MONITORING OUTCOMES}

Stream temperature data improve understanding of baseline conditions, provide a context to evaluate success of restoration efforts, and contribute to regional monitoring networks such as the NorWeST effort. For example, volunteers are collecting baseline data in many streams in the southwestern United States, including existing populations of Rio Grande cutthroat trout (Oncorhynchus clarki virginalis) in New Mexico and potential reintroduction sites

\section{Figure 4}

Wyoming stream temperature monitoring opportunities map provided by staff to volunteers, showing proposed priorities and existing temperature monitoring stations. The map is also provided as an interactive webmap.

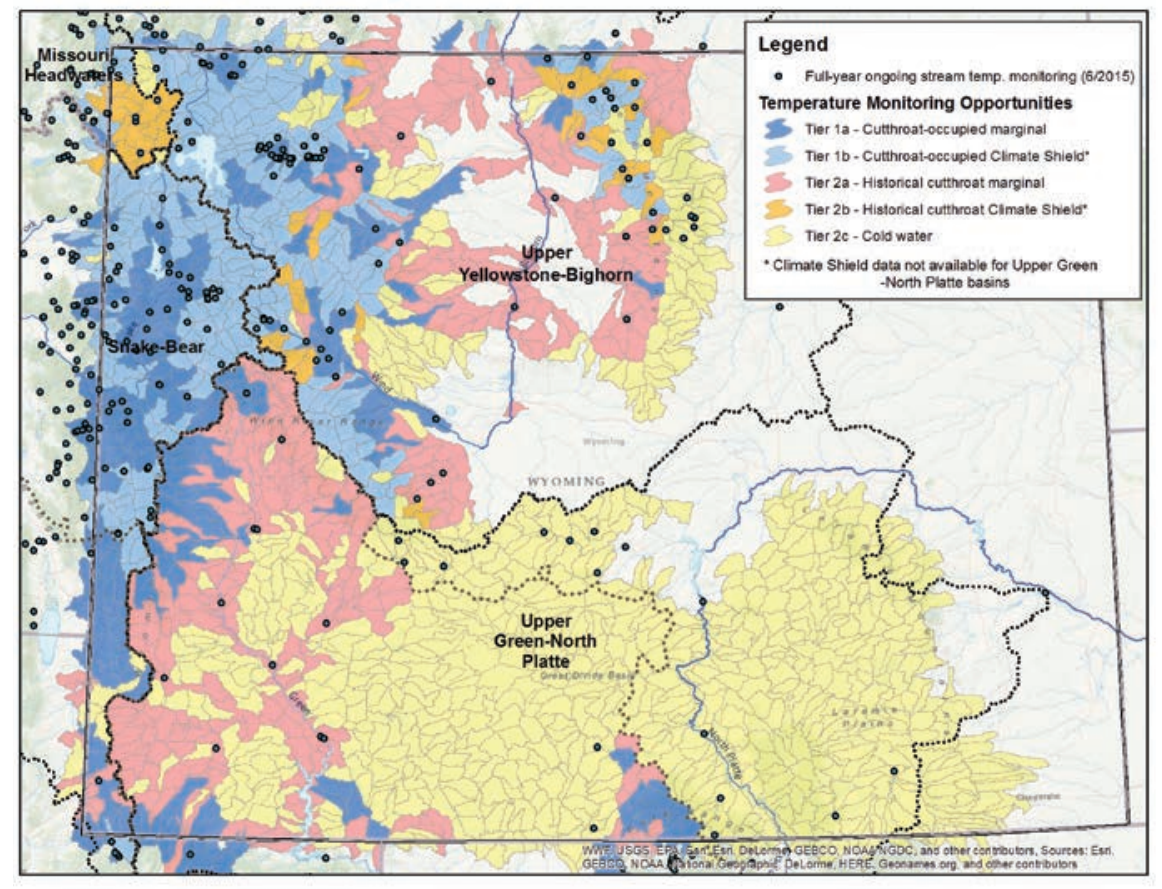

for Gila trout (Oncorhynchus g. gilae) in coordination with the Arizona Game and Fish Department. These data will also contribute to development of regional stream temperature models of likely future conditions that can guide restoration and reintroduction efforts for southwestern native trout (Isaak et al. 2014).

Individual participants and local TU chapters benefit from new knowledge of the conditions and restoration needs of their local streams. Stream temperature data also provides educational opportunities with local schools and Science, Technology, Engineering, and Mathematics (STEM) activities. The organization benefits from the partnerships volunteers create with local natural resource management agencies, information provided through monitoring, and as members become better-informed advocates on conservation issues with a national scope, such as climate change.

\section{ENGAGING THE ANGLING COMMUNITY}

The American Sportfishing Association (2013) estimates that 33 million Americans 16 years or older took part in fishing in 2011, including more than 27 million participating in freshwater angling. Trout Unlimited members comprise a very small subset of anglers, yet TU's modest citizen science programs demonstrate the potential for anglers to contribute to water quality protection through active engagement in monitoring programs. Not only does increased angler participation result in opportunities to improve stream condition, but developing angler-based monitoring programs have numerous organizational benefits that should not be overlooked.

Both the shale gas monitoring and stream temperature programs have resulted in increased engagement by TU members and partnership opportunities with local, state, and federal agencies. Both projects provide strong motivation for anglers to participate. In the Marcellus Shale region, energy development threatens eastern brook trout streams and local fishing opportunities. The desire to protect trout streams encourages angler participation to ensure the future of their sport. Because stream temperature is critical to trout and salmon, 
there are many local volunteer projects that focus on improving water temperatures for coldwater-dependent fishes, as well as a strong interest in establishing baseline temperature conditions in order to understand future development impacts. In this case, angler participation may be motivated not only by a desire to protect local fishing opportunities, but also by a desire to document the effectiveness of local restoration efforts, or to provide data for education or youth programs. The roles and responsibilities of national staff vary between the projects but there are many common elements that seem to apply to all TU angler science programs (table 1).

Participation in citizen science has increased remarkably over the past decade (Bonney et al. 2014; Tulloch et al. 2013), and the advancement of technology continues to drive the growth of these programs (Nature 2015) and opportunities for resource protection. Citizen science can be particularly effective when data are collected over longer spatial and temporal scales (Tulloch et al. 2013) and core groups of motivated volunteers participate (Ely 2008). However, organizational issues are often cited as a challenge for citizen science opportunities (Conrad and Daoust 2008; Conrad and Hilchey 2011). National, member-based angling and conservation organizations can be a stable platform for the successful implementation of citizen science projects due to their organizational structure and a passionate membership base. However, an understanding of the most effective roles of an organization's staff in a citizen science program and how to translate the

\section{Figure 5}

Stream temperature monitoring kit for volunteers containing Tidbit data loggers, manual, computer shuttle, software, and underwater housings.

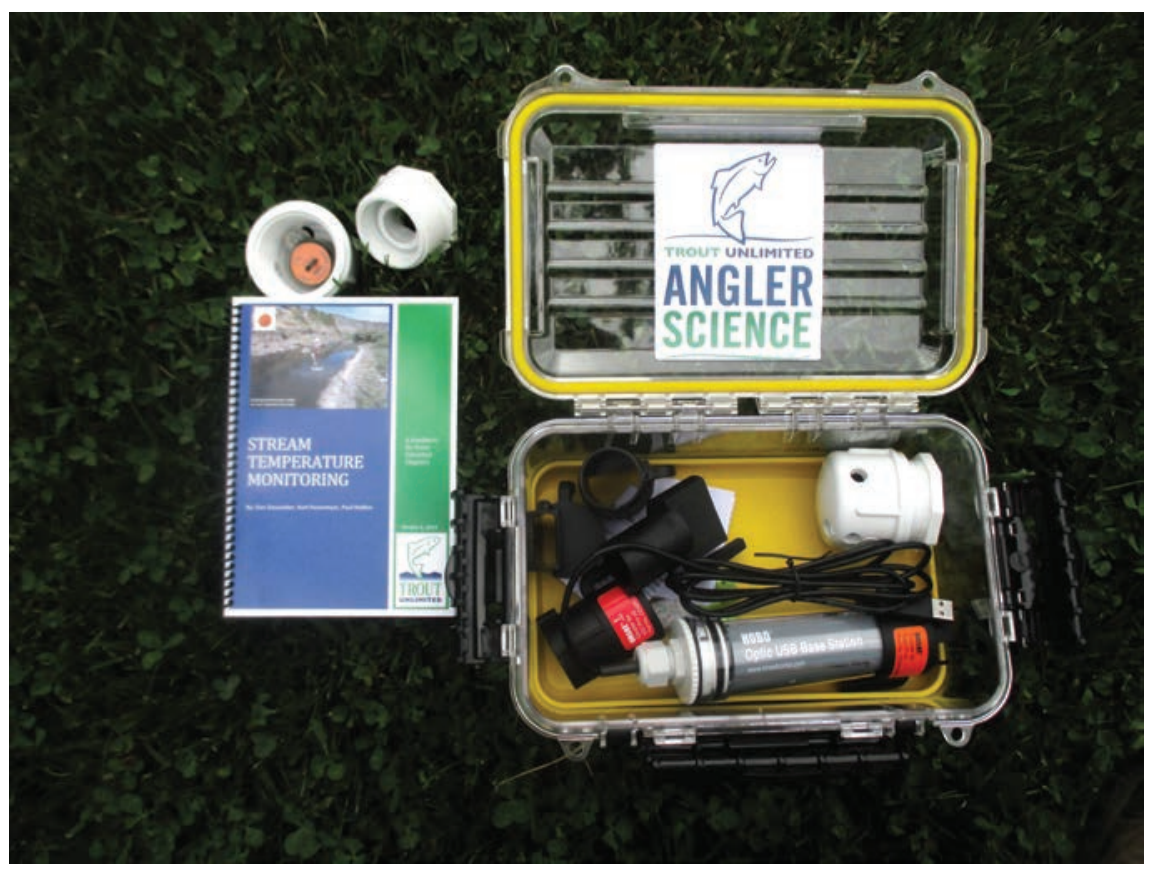

interest of its membership into greater participation in a citizen science program is often lacking.

The roles of TU staff that are common across our citizen science projects are outlined in table 1 . These roles will vary among projects and organizations, but the general framework should be of interest to those organizations with members driven by conservation or sporting interests. In general, the role of staff relates to resolving the three main challenges in citizen science: (1) organizational issues, (2) data collection issues, and (3) data use issues (Conrad and Hilchey 2011).
Protocols for citizen science monitoring projects should be kept simple in order to maximize data quality and maintain volunteer interest (Penrose and Call 1995). Both programs outlined herein make use of simple protocols, standardized equipment, and assistance from partners (accredited laboratories for sample analyses or US Forest Service lab for compiling temperature data). These steps, taken in conjunction with close partnerships with local, state, and federal management agencies and academic institutions, have allowed for data collected by volunteers to be incorporated into larger information

\section{Table 1}

Roles and responsibilities of national staff for chapter-based organizations' citizen science efforts and resulting benefits to organizations and natural resources.

\begin{tabular}{|c|c|}
\hline Staff roles and responsibilities & Resulting organizational and resource benefits \\
\hline Develop citizen science opportunities that are integrated with agency needs & Increases agency partnerships \\
\hline Market the various citizen science opportunities to membership base & Diversifies chapter activities and attracts new (and more diverse) members \\
\hline $\begin{array}{l}\text { Provide training, manuals, web mapping, smartphone apps, and other } \\
\text { forms of technical assistance }\end{array}$ & $\begin{array}{l}\text { Encourages participation and ensures quality control and consistent } \\
\text { methodologies }\end{array}$ \\
\hline Gather and manage data collected by citizen science efforts & Ensures data collected contribute beyond local scale \\
\hline Provide discussion forum for participants & $\begin{array}{l}\text { Encourages broader communication among participants and learning } \\
\text { between chapters }\end{array}$ \\
\hline Disseminate results to participants and partner organizations & Provides positive feedback and encourages continued participation \\
\hline
\end{tabular}


networks used to inform decision makers. Partnerships enhance the successful implementation of citizen science projects and facilitate long-term data collection and work across larger spatial scales that cross political boundaries (Shirk et al. 2012).

Maintaining volunteer engagement in citizen science programs is often difficult for long-term projects (Conrad and Daoust 2008). TU's membership is primarily comprised of anglers and the initial motivation for participation in citizen science opportunities is to protect and ensure the future of their sport. Although citizen science programs have continued to grow at TU, only a small percentage of the general membership currently participates in the available angler science opportunities. Continued outreach through the dissemination of results, publications targeted at the general public (Kolok et al. 2011), and effective marketing (McKenzie-Mohr 2000; Cooper et al. 2007) have been shown to be important for maintaining motivation and increasing engagement and should be an important focus for expanding citizen science projects.

Membership-based organizations have a strong potential to increase participation in citizen science activities where these activities have a demonstrated link to the desires of their members. When most effective, citizen science activities not only improve science capacity and help solve resource problems, but provide organizational benefits as described above that result in a more engaged and more informed membership base that produces more effective advocates for better resource stewardship. That being the case, membership-based conservation and angling organizations should consider investing additional resources to promote and coordinate citizen science activities among their members.

\section{ACKNOWLEDGEMENTS}

Trout Unlimited thanks the many federal and state agencies and our nonprofit organization partners working on the Marcellus Shale monitoring program and the NorWeST Stream Temperature Network. We thank Katy Dunlap and Rickie White for their critical reviews of earlier versions of this manuscript. Most importantly, we want to acknowledge the willingness of our volunteers to donate their time and passion to protecting our streams and their watersheds. This work was supported in part by the National Fish and Wildlife Foundation and Trout Unlimited's Coldwater Conservation Fund.

\section{REFERENCES}

American Sportfishing Association. 2013. Sportfishing in America: An economic force for conservation. Alexandria, VA: American Sportfishing Association.

Behnke, R.J. 2002. Trout and Salmon of North America. New York: The Free Press.

Bonney, R., J.L. Shirk, T.B. Phillips, A. Wiggins, H.L. Ballard, A.J. Miller-Rushing, and J.K. Parrish. 2014. Next steps for citizen science. Science 343:1436-1437.

Clemens, B.J. 2015. A survey of steelhead age and iteroparity rates from a volunteer angler program in the Willamette River Basin, Oregon. North American Journal of Fisheries Management 35:1046-1054.

Conrad, C., and T. Daoust. 2008. Community-based monitoring frameworks: Increasing the effectiveness of environmental stewardship. Environmental Management 41:356-358.

Conrad, C., and K.G. Hilchey. 2011. A review of citizen science and community-based environmental monitoring: Issues and opportunities. Environmental Monitoring and Assessment 176:273-291.

Cooper, C.B., J. Dickinson, T. Phillips, and R. Bonney. 2007. Citizen science as a tool for conservation in residential ecosystems. Ecology and Society 12:11-21.

Ely, E. 2008. Volunteer monitoring and the democratization of science. The Volunteer Monitor 19:1-5.

Ferguson, I. 2013. Macroinvertebrate monitoring, Salmonberry River (Nehalem Basin), Oregon. Portland, OR: Native Fish Society.

Fesenmyer, K.A. 2014. Central Appalachians Conservation Success Index. Arlington,VA:Trout Unlimited.

Firehock, K., and J. West. 1995. A brief history of volunteer biological water monitoring using macroinvertebrates. Journal of the North American Benthological Society 14:197-202.

Isaak, D.J., M.K.Young, D. Nagel, and D. Horan. 2014. Coldwater as a climate shield to preserve native trout through the 21st Century. In Proceedings of the Wild Trout XI Symposium, Bozeman, Montana, 22 September 2014, pp. 110-116.

Jacobson, S., J. Marshall, D. Dalrymple, F. Kawasaki, D. Pearse, A. Abadia-Cardoso, and J. Carlos Garza. 2014. Genetic analysis of trout (Oncorhynchus mykiss) in southern California coastal rivers and streams. Report to California Department of Fish and Wildlife. San Diego, CA: Trout Unlimited.

Kolok, A.S., H.L. Schoenfuss, C.R. Propper, and T.L. Vail. 2011. Empowering citizen scientists: The strength of many in monitoring biologically active environmental contaminants. BioScience 61:626-630

McKenzie-Mohr, D. 2000. Fostering sustainable behavior through community-based social marketing. American Psychologist 55:531-537.

Nature. 2015. Rise of the citizen scientist. Nature 524:265

Nerbonne, J.F., and B. Vondracek. 2003. Volunteer macroinvertebrate monitoring: Assessing training needs through examining error and bias in untrained volunteers. Journal of North American Benthological Society 22:152-163.

Newman, G., A. Wiggins, A. Crall, E. Graham, S. Newman, and K. Crowston. 2012. The future of citizen science: Emerging technologies and shifting paradigms. Frontiers in Ecology and the Environment 10:298-304.

Penrose, D., and S. Call. 1995. Volunteer monitoring of benthic macroinvertebrates: Regulatory biologists' perspectives. Journal of the North American Benthological Society 14:203-209.

Shirk, J.L., H.L. Ballard, C.C. Wilderman, T. Phillips, A.Wiggins, R. Jordan, E. McCallie, M. Minarchek, B.V. Lewenstein, M.E. Krasny, and R. Bonney. 2012. Public participation in scientific research: A framework for deliberate design. Ecology and Society $17(2): 29$.

Trout Unlimited. 2015. State of the trout:A report on the status and trends of native trout in the United States. Arlington, VA: Trout Unlimited.

Tulloch, A.I.T., H.P. Possingham, L.N. Joseph, J. Szabo, and T.G. Martin. 2013. Realizing the full potential of citizen science monitoring programs. Biological Conservation 165:128-138.

US Environmental Protection Agency. 2016. National rivers and streams assessment 20082009: A collaborative survey. Washington, DC: EPA Office and Water and Office of Research and Development. http://www.epa.gov/ national-aquatic-resource-surveys/nrsa.

Williams, J.E., A.L. Haak, N.G. Gillespie, and W.T. Colyer. 2007. The Conservation Success Index: Synthesizing and communicating salmonid condition and management needs. Fisheries 32:477-492. 